\title{
Stress Analysis of Ceramic Laminate Veneer for Diastema Closure with Different Extensions and Different Directions of Applied Load
}

\author{
Adel A. El Badawy ${ }^{1, *}$, Mohammed H. Abd El Aziz ${ }^{2}$ \\ ${ }^{1}$ Department of Crown and Bridge, Al - Azhar University, Cairo, Egypt \\ ${ }^{2}$ Department of Substitutive Dental Sciences, Taibah University, Madinah, Saudi Arabia \\ *Corresponding author: dr.elbadawy@gmail.com
}

\begin{abstract}
Purpose: To analyze stress distribution on the IPS e. max (lithium di silicate) laminate veneer used for diastema closure with different free median extensions and different extensions of proximal preparation using two directions of applied force. Statement of the problem: Closure of large median diastema by laminate veneer will increase stress intensity on the unsupported mesial extension. Materials and Methods: Finite element model of unprepared maxillary central incisor was made, by deletion method, the labial surface was reduced by $0.5 \mathrm{~mm}$. and is taken up to the height of the incisal edge (feather design), then, the basic geometric configurations of different laminate veneer designs and its dimensions in millimeters were introduced into the ANSYS software program to obtain the different nine models from three proximal extensions (1, 1.5 and $2 \mathrm{~mm}$ ) and three unsupported median extensions $(0.5,1$ and $1.5 \mathrm{~mm}$ ), then the stress distributions were evaluated by applying load of $100 \mathrm{~N}$ at two angulations $\left(60^{\circ}\right.$ and $125^{\circ}$ ). Results: In case of $60^{\circ}$ applied load the highest stress value was recorded in Model 3 (veneer with $1 \mathrm{~mm}$ labio - palatal extension with 1.5 free median extension, $30.95 \mathrm{Mpa}$ ) where The lowest stress value was recorded in Model 7 (veneer with $2 \mathrm{~mm}$ labio - palatal extension with 0.5 free median extension, $20.15 \mathrm{Mpa}$ ). Statistically, there was a significant difference between tested models ( $\mathrm{P}$ at the level 0.05 ) except in cases of model 1, 4 and 7 which exhibited no statistical significant difference (P > 0.05). In case of $125^{\circ}$ applied load the highest stress value was recorded in Model 3 (veneer with $1 \mathrm{~mm}$ labio - palatal extension with 1.5 free median extension, $53.61 \mathrm{Mpa}$ ) where The lowest stress value was recorded in Model 7 (veneer with $2 \mathrm{~mm}$ labio - palatal extension with 0.5 free median extension, 39.27 Mpa). Statistically, there was a significant difference between tested models (P at the level 0.05) except in cases of model 4, 5 and 8 which exhibited no statistical significant difference $(\mathrm{P}>0.05)$. Conclusion: Stress is concentrated on the free median extension, incisal edge, and the mesio - labio incisal point angle. The stress intensity increase in the following cases: - (1) increase in free median extension of the veneer, (2) increase in angulation of applied force, (3) decrease in proximal extension of laminate veneer.
\end{abstract}

Keywords: stress analysis, diastema closure, laminate veneer

Cite This Article: Adel A. El Badawy, and Mohammed H. Abd El Aziz, "Stress Analysis of Ceramic Laminate Veneer for Diastema Closure with Different Extensions and Different Directions of Applied Load." International Journal of Dental Sciences and Research, vol. 6, no. 2 (2018): 33-38. doi: 10.12691/ijdsr-6-2-3.

\section{Introduction}

Median diastema (which can be defined as a median space greater than $0.5 \mathrm{~mm}$ between the proximal surfaces of the two central incisors), [1] is certainly psychologically annoying for affected individuals as it is easily noticed and esthetically displeasing. [2] Due to the different applications of dental ceramics in dentistry, numerous dental ceramics with variable mechanical properties and chemical composition have been presented [3]. They are generally categorized into glass and high-strength core ceramics, onto which an esthetic ceramic layer must be applied to attain a natural appearance $[4,5,6]$. Lithium disilicates are glass ceramics that are currently recommended due to the ability to produce thin layers exhibiting an excellent esthetic performance [7]. Regarding the best place of interproximal margin of the laminate veneer, traditionally, the proximal preparation of laminate veneer stop labial to the contact area, But, in some cases we have to make the veneer tooth interface more palatal, [8] there is a range of authors opinions from a preparation that end before the interproximal contact to a slight opening of this contact. [9] Vanlioğlu, [10] postulated that, breaking the contact may be necessary to clear the contact in case of changing the shape or position of teeth and in case of multiple veneers preparation, while Garber, [11] recommended the preparation extension passing two thirds of proximal surface as a more appropriate depth. Most authors, $[12,13,14]$ postulated that, palatal extension of the proximal preparations is necessary to permit technician to enhance the optical illusion of diastema closure. Robbins, [13] described these palatal extensions by that, the greater 
the median space to be closed, the farther the extension must be to the palatal. This study was directed to evaluate stress distribution on the IPS empress ceramic laminate veneer used for diastema closure with different free median extensions and different extensions of proximal preparation using two directions of applied force.

\section{Materials and Methods}

Maxillary right central incisor with $26 \mathrm{~mm}$ length (free of dental caries, restorations and incisal attrition) was selected and fixed at a glass slab $(2 \times 2 \mathrm{~cm})$ with a piece of wax. Using dental surveyor, the tooth was aligned with their axis perpendicular to the horizontal plane of the mold, then, a plastic mold $(2 \times 2 \times 3 \mathrm{~cm})$ was assembled over the glass slab. Finally, the mold was filled entirely with molten wax. Computerized tomography (CT) image was performed (CS 9300, Carestream, AGXL012) with image quality $(120 \mathrm{kV}, 150 \mathrm{~mA})$ and slice volume of $0.5 \mathrm{~mm}$ thickness to divide the tooth into 52 sections. Scanning was performed in a labio - palatal direction starting from the incisal edge up to apical foramen to obtain 53 image levels $(0,1,2,3,4 \ldots \ldots .52 \mathrm{~mm})$. From Computerized tomography scan, $1240 \mathrm{~K}$ points were obtained, each $\mathrm{K}$ point has a three distances, $\mathrm{x}, \mathrm{y}$, and $\mathrm{z}$. $\{\mathrm{x}$ : is the distance from " $\mathrm{X}$ " axis, $\mathrm{y}$ : is the distance from " $\mathrm{Y}$ " axis, while $\mathrm{z}$ : is the slice level $(0.5 \mathrm{~mm}$ increase with each level) $\}$. The collected $\mathrm{x}, \mathrm{y}$, and $\mathrm{z}$ distances were introduced into special program for stress analysis (ANSYS 5.4 finite element software) to obtain three-dimensional finite element model for maxillary central incisor divided into cubical volumes "as seen in Figure 1". The volumes were digitally refined and automatically mashed with eight nodes brick for each with three degrees of freedom per nodes, finally resulting the original finite element model for unprepared maxillary central incisor with its internal morphology including (131294) elements and (202464) nodes "as seen in Figure 2". By deletion method, the labial surface was reduced by 0.5 $\mathrm{mm}$. and is taken up to the height of the incisal edge but the edge is not reduced (feather design) "as seen in Figure 3". And from the spongy bone volume, $0.25-\mathrm{mm}$ periodontal ligament, $0.25-\mathrm{mm}$ lamina dura, and $1.5 \mathrm{~mm}$ cortical bone were developed. The remaining bone was modeled as cancellous type $[15,16]$ and a cylindrical bone section of $20 \mathrm{~mm}$ height and $10 \mathrm{~mm}$ diameter was modeled.

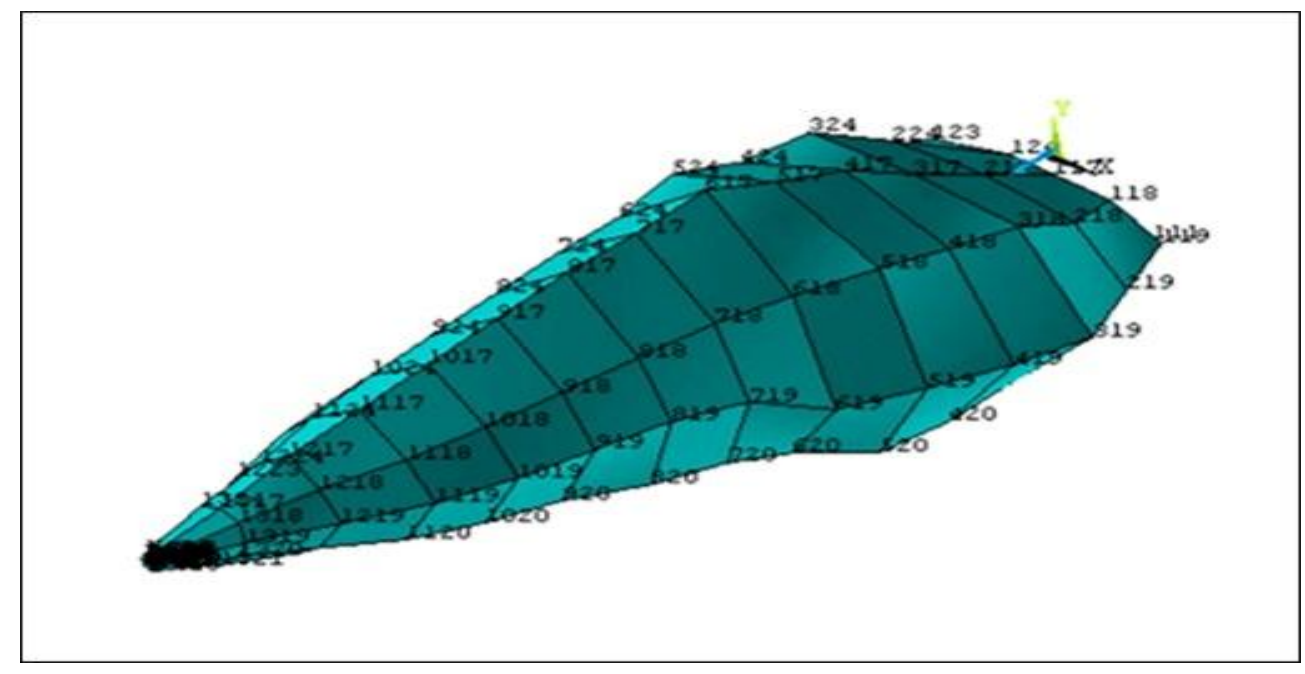

Figure 1.

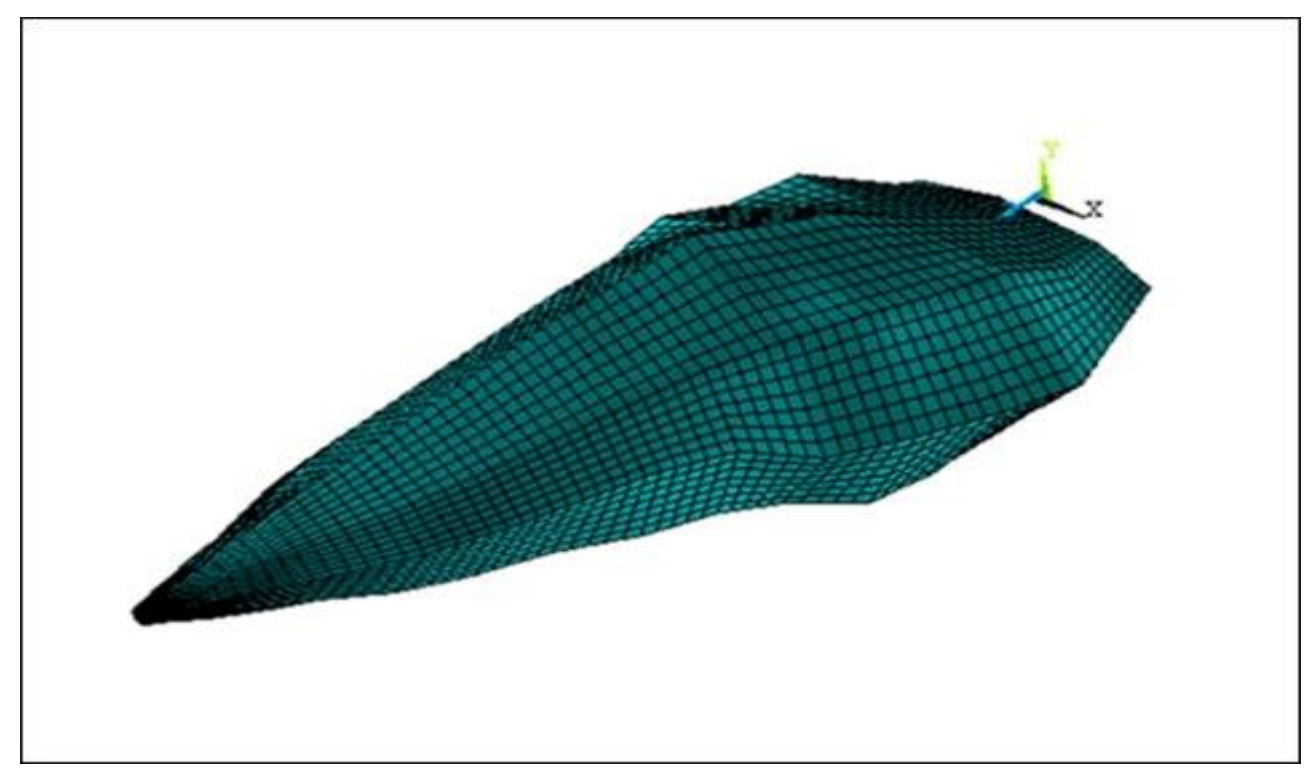

Figure 2 


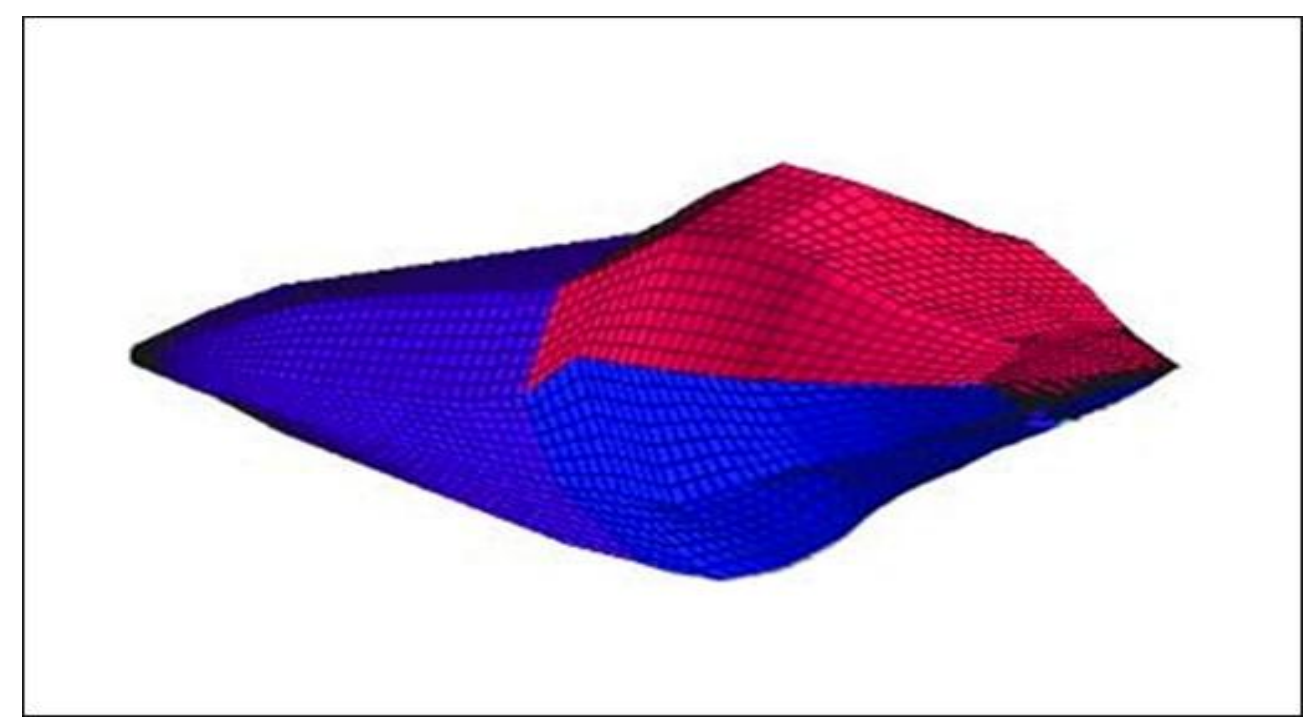

Figure 3.

The basic geometric configurations of the different laminate veneer designs and its dimensions in millimeters in addition to $30 \mu$ thickness of bonding agent layer with $100 \mu$ thickness of resin cement layer were introduced into the ANSYS software program to obtain the nine models "as seen in Table 1". Young's Modulus, and Poisson's ratio of the tooth components as well as the used materials" as seen in Table 2", [17,18,19] were introduced to the ANSYS software program which in turn calculated stresses under a load of $100 \mathrm{~N}$ at $60^{\circ}$ (tearing) and $125^{\circ}$ (protrusion) [20] to identify maximum Von Mises equivalent stresses $($ in $\mathrm{X}, \mathrm{Y}, \mathrm{Z}$ directions $)=$

$$
1 / 2[(\sigma 1-\sigma 2) 2+(\sigma 2-\sigma 3) 2+(\sigma 3-\sigma 1) 2]
$$

where $\sigma 1, \sigma 2$, and $\sigma 3$ are principal stresses taking in consideration that, $\sigma 1>\sigma 2>\sigma 3$. [21] The data were collected and statistically analyzed by ANOVA one-way test using statistical-package of social science (SPSS) statistic software (SPSS for windows, version 21.0, SPSS Inc. Chicago).

Table 1.

\begin{tabular}{|c|c|}
\hline Model & Description \\
\hline M (1) & $\begin{array}{l}\mathbf{1} \mathbf{~ m m} \text { proximal extension and } \mathbf{0 . 5} \mathbf{~ m m} \text { free median } \\
\text { extension }\end{array}$ \\
\hline M (2) & $\begin{array}{l}\mathbf{1} \mathbf{~ m m} \text { proximal extension and } \mathbf{1} \mathbf{~} \mathbf{m m} \text { free median } \\
\text { extension }\end{array}$ \\
\hline M (3) & $\begin{array}{l}1 \mathrm{~mm} \text { proximal extension and } \mathbf{1 . 5} \mathbf{~ m m} \text { free median } \\
\text { extension }\end{array}$ \\
\hline M (4) & $\begin{array}{l}1.5 \mathrm{~mm} \text { proximal extension and } \mathbf{0 . 5} \mathbf{~ m m} \text { free } \\
\text { median extension }\end{array}$ \\
\hline M (5) & $\begin{array}{l}\mathbf{1 . 5} \mathbf{~ m m} \text { proximal extension and } \mathbf{1} \mathbf{~} \mathbf{m} \text { free median } \\
\text { extension }\end{array}$ \\
\hline M (6) & $\begin{array}{l}\mathbf{1 . 5} \mathbf{~ m m} \text { proximal extension and } \mathbf{1 . 5} \mathbf{~ m m} \text { free } \\
\text { median extension }\end{array}$ \\
\hline M (7) & $\begin{array}{l}\mathbf{2} \mathbf{~ m m} \text { proximal extension and } \mathbf{0 . 5} \mathbf{~ m m} \text { free median } \\
\text { extension }\end{array}$ \\
\hline M (8) & $\begin{array}{l}\mathbf{2} \mathbf{~ m m} \text { proximal extension and } \mathbf{1} \mathbf{~} \mathbf{m} \text { free median } \\
\text { extension }\end{array}$ \\
\hline M (9) & $\begin{array}{l}\mathbf{2} \mathbf{~ m m} \text { proximal extension and } \mathbf{1 . 5} \mathbf{~ m m} \text { free median } \\
\text { extension }\end{array}$ \\
\hline
\end{tabular}

Table 2.

\begin{tabular}{|l|c|c|}
\hline Material & $\begin{array}{c}\text { Modulus of elasticity } \\
\text { Mpa }\end{array}$ & Poisson's ratio \\
\hline Enamel [17] & 84100 & 0.41 \\
\hline Dentin [17] & 18600 & 0.31 \\
\hline Pulp [17] & 2 & 0.45 \\
\hline Periodontal ligament [18] & 68.9 & 0.45 \\
\hline Cortical bone [18] & 13700 & 0.30 \\
\hline Cancellous bone [18] & 13700 & 0.30 \\
\hline IPS e. max core [18] & 65000 & 0.24 \\
\hline IPS e. max veneer [18] & 65000 & 0.24 \\
\hline Resin cement [19] & 18.3 & 0.33 \\
\hline
\end{tabular}

\section{Results}

\subsection{Qualitative analysis}

In all tested finite element models representing the nine different designs (in both directions of applied load), the results exhibited that, the highest stress concentration appeared at the level of the laminate veneer then decreased towards the resin cement layer up to the tooth structure. Within the laminate veneer level, the stress was higher at the free median extension, incisal region and mesio - labio - incisal point angle, then gradually and significantly decreased and uniformly distributed along the labial wall giving an indication of good and uniform stress distribution. After dispersing along the adhesive interface in the same direction of the applied force and transferring the stress to a lower value, it was concentrated again at the cervical area "as seen in Figure 4". In general, stress values on the IPS e. max laminate veneer for all models, increase by the following variables (1) increasing the angulation of applied force, (2) decreasing the proximal preparation extension, (3) increasing the free median extension for diastema closure.

Table 3 reports Von Mises equivalent stress values recorded on the IPS e.max laminate veneer in the simulated finite element models with the tested nine 
different proximal designs and the two angles of applied load in (Mpa). "As shown in Table 3", Von Mises equivalent stress values on the IPS e.max laminate veneer for all models, increase by the following variables (1) increasing the angulation of applied force, (2) decreasing the proximal preparation extension, (3) increasing the free median extension for diastema closure.

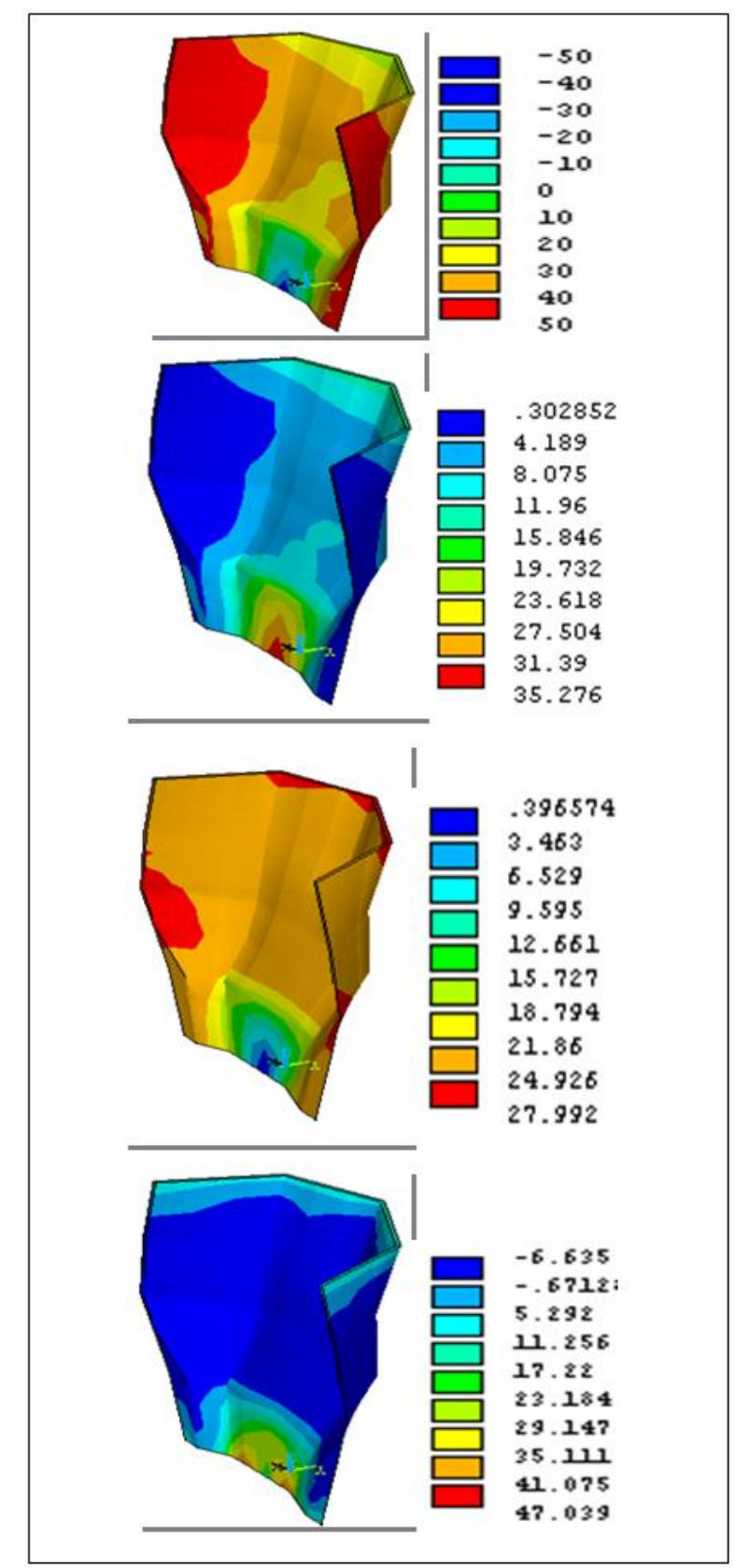

Figure 4

Table 3.

\begin{tabular}{|c|c|c|c|c|c|c|c|c|}
\hline & & & \multicolumn{6}{|c|}{ Mesial extension (mm) } \\
\hline & & & \multicolumn{2}{|c|}{0.5} & \multicolumn{2}{|c|}{1.0} & \multicolumn{2}{|c|}{1.5} \\
\hline \multirow{6}{*}{ 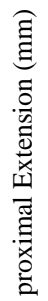 } & \multirow{2}{*}{$\stackrel{0}{-}$} & $60^{\circ}$ & \multirow{2}{*}{$\bar{\Sigma}$} & 20.23 & \multirow{2}{*}{$\stackrel{\mathcal{Z}}{\Sigma}$} & 22.73 & \multirow{2}{*}{$\sum_{\Sigma}^{M}$} & 30.95 \\
\hline & & $125^{\circ}$ & & 47.77 & & 48.27 & & 53.61 \\
\hline & \multirow{2}{*}{$\stackrel{n}{n}$} & $60^{\circ}$ & \multirow{2}{*}{$\sum_{\Sigma}^{ \pm}$} & 20.16 & \multirow{2}{*}{$\stackrel{n}{\Sigma}$} & 21.51 & \multirow{2}{*}{$\stackrel{0}{\Sigma}$} & 30.08 \\
\hline & & $125^{\circ}$ & & 44.32 & & 45.87 & & 52.99 \\
\hline & \multirow{2}{*}{$\stackrel{\circ}{\circ}$} & $60^{\circ}$ & \multirow{2}{*}{$\bar{\Sigma}$} & 20.15 & \multirow{2}{*}{$\sum_{\Sigma}^{\infty}$} & 20.25 & \multirow{2}{*}{$\stackrel{g}{\Sigma}$} & 29.66 \\
\hline & & $125^{\circ}$ & & 39.27 & & 45.34 & & 52.23 \\
\hline
\end{tabular}

\subsection{Qualitative Analysis}

Table 3 and Figure 5 showed Von Mises equivalent stress values recorded on the IPS e. max laminate veneer in the finite element model with the tested nine designs at two directions of applied load in Mpa. The results of this study showed that, Von Mises equivalent stress value in case of $60^{\circ}$ applied load for all tested models were lower than that in case of $125^{\circ}$ applied load.

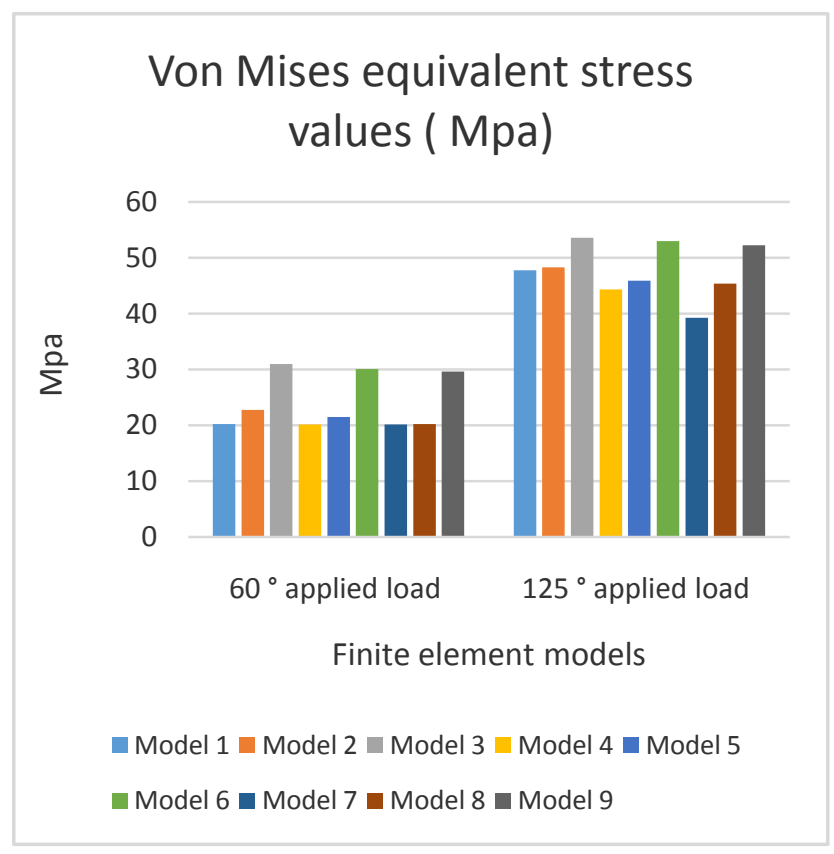

Figure 5.

In case of $60^{\circ}$ applied load the highest stress value was recorded in Model 3 (veneer with $1 \mathrm{~mm}$ labio - palatal extension with 1.5 free median extension, $30.95 \mathrm{Mpa}$ ) where the lowest stress value was recorded in Model 7 (veneer with $2 \mathrm{~mm}$ labio - palatal extension with 0.5 free median extension, 20.15 Mpa). Statistically, there was a significant difference between tested models ( $\mathrm{P}$ at the level 0.05 ) except in cases of model 1,4 and 7 which exhibited no statistical significant difference $(\mathrm{P}>0.05)$.

In case of $125^{\circ}$ applied load the highest stress value was recorded in Model 3 (veneer with $1 \mathrm{~mm}$ labio - palatal extension with 1.5 free median extension, 53.61 Mpa) where The lowest stress value was recorded in Model 7 (veneer with $2 \mathrm{~mm}$ labio - palatal extension with 0.5 free median extension, 39.27 Mpa). Statistically, there was a significant difference between tested models ( $\mathrm{P}$ at the level 0.05) except in cases of model 4,5 and 8 which exhibited no statistical significant difference $(\mathrm{P}>0.05)$.

\section{Discussion}

The finite element analysis is a numerical method for study of stress distribution. The advantage of this method is that, great number of variables can be studied on the same model, decreasing the risk of experimental errors. The internal stress can be analyzed whatever the dimensions and shape of the structure to be studied, which is a problem found when dealing with the human body. [22] Many authors accepted the traditional design of 
laminate veneer which extends interproximal stopping before the contact area to allow simple, quick, and conservative reduction of tooth structure, at the same time exclude the need for temporization. But this design is not appropriate for every situation as in diastema closure where we have to extend the interproximal preparation involving the contact area. [23]

In this study, maxillary central incisor has been selected for finite element modeling because veneers are commonly indicated for it, also, at the same time, most of laminate veneer failure occur in this tooth. [24] Uniform labial reduction was done to ensure the whole preparation confined into enamel layer. This simulate clinical situation of better bonding without veneer over contouring. $[25,26,27]$ The result of this study showed that, the stresses concentrated on the laminate veneer level and significantly decreased towards the resin cement layer up to the tooth structure in all tested preparation designs and the highest stress concentration appeared at the level of the laminate veneer. This is due to the overall mechanical properties of the IPS e.maxwhich is high in modulus of elasticity (nearly $95 \mathrm{Gpa}$ ) than that of resin cement and tooth structure, this result is in agreement with Zarone et al, [28] and Troedson and Dérand [29].

The results of this study showed that, with the increase of proximal extension of the preparation, the stress concentration decreased. This is may be attributed to that, the presence of thick enamel band at the interproximal area that permit extension to the palatal aspect without dentin exposure.

This result is in agreement with that of other authors. $[12,13,14]$ On the other hand, the results of this study are incompatible with that of other studies, [30,31] in which the traditional inter proximal preparation design without involvement of contact area exhibited better fracture resistance than in proximal preparation with contact involvement attributing their results by that, the stress levels increase on the incisal edge with an increase in extension of the interproximal preparation (it should be noted that, they used porcelain material rather than IPS e max press that has been used in this study).

Regarding to increasing in free median extension closing the diastema, the results of the study exhibited that, compressive stress levels increase on the mesio - labial incisal angle in case of $60^{\circ}$ applied load (tearing) and became more in case of $125^{\circ}$ applied load (protrusion), this is may be due to increasing in stress bearing surface area of the laminate veneer and presence of laminate veneer material un supported by tooth structures.

From the other hand, tensile stress levels decrease with an increase in proximal extension into palatal direction, this is probably because stress is load divided by area, and an increased area with extended laminate veneer helps to distribute the load and produce lower tensile stresses, also, in case of $60^{\circ}$ applied load the stress distribution is better than that of $125^{\circ}$ applied load. This results are compatible with that of Chander and Padmanabhan [31].

\section{Conclusion}

Within the limitations of this study, the following conclusions have been found:
1. Stress is concentrated on the free median extension, incisal edge, and the mesio - labio - incisal point angle.

2. The stress intensity increase in (a) increase in free median extension of laminate veneer, (b) increase in angulation of applied force, (c) decrease in proximal extension of laminate veneer.

\section{References}

[1] Keene HJ. Distribution of diastemas in the dentition of man. Am J Phys Anthropol. 1963; 21: 437-441.

[2] Shirish MB, Chanchal S, Prashant B. Closing a Large Maxillary Median Diastema using Bapat Power Arm. Inter J Clin Ped Dent.2017; 10(2): 201-204.

[3] Hahnel S. Surface characterization of dental ceramics and initial streptococcal adhesion in vitro. Dent Mater. 2009; 25: 969-975.

[4] Spear F, Holloway J. Which all-ceramic system is optimal for anterior esthetics? J Am Dent Assoc.2008; 139: 19-24.

[5] Denry I, Holloway JA. Ceramics for Dental Applications: A Review. Materials.2010; 3: 351-368.

[6] Tang X. Effects of ageing on surface textures of veneering ceramics for zirconia frameworks. J Dent.2012; 40: 913-920.

[7] Shenoy A, Shenoy N. Dental ceramics: An update. J Conserv Dent 2013; 13: 195-203.

[8] Jeffrey SR. Full veneer versus traditional veneer preparation: A discussion of interproximal extension. J Prosthet Dent. 1997; 78: 545-9.

[9] Radz GM. Minimum thickness anterior porcelain restorations. Dent Clin North Am. 2011; 55(2): 353-370.

[10] Vanlioğlu B, Özkan Y. Minimally invasive veneers: current state of the art Clinical, Cosmetic and Investigational. Dent J. 2014; 6: 101-107.

[11] Garber DA. Porcelain veneer to prepare or not prepare? That is the question. Conl Esthet Dent. 1996; 2: 1-7.

[12] Chalifoux PR. porcelain veneers. Curr opin cosmet Dent. 1994; 58-66.

[13] Rubbins JW. Porcelain veneer: Fundamental of operative dentistry, contemporary approach. Chicago, Quintessence publishing co, 1996; 849-71

[14] Gribble AR. Multiple diastema management, an interdisciplinary approach. J Esthet Dent. 1994; 6:97-102.

[15] Eraslan O, Aykent F, Yücel MT, Akman S. The finite element analysis of the effect of ferrule height on stress distribution at post-and-core-restored all-ceramic anterior crowns. Clin Oral Invest. 2009; 13: 223-227.

[16] Tada S, Stegaroiu R, Kitamurs E, Miyakawa O, Kusakari H. Influence of implant design and bone quality on stress/ strain distribution in bone around implants: a 3-dimensional finite element analysis. Int J Oral Maxillofac Implants. 2003; 18: 357-368.

[17] N. Gopi Chander, MDS1 \& T. V. Padmanabhan, MDS2 Finite Element Stress Analysis of Diastema Closure with Ceramic Laminate Veneers. J Prosthod. 2009; 18: 577-581.

[18] Eraslan O, Aykent F, Yücel MT, Akman S. The finite element analysis of the effect of ferrule height on stress distribution at post-and-core-restored all-ceramic anterior crowns. Clin Oral Invest. 2009; 13: 223-227.

[19] Li LL, Wang ZY, Bai ZC, Mao Y, Gao B, Xin HT. Threedimensional finite element analysis of weakened roots restored with different cements in combination with titanium alloy posts. Chin Med J 2006; 119: 305-11.

[20] Fernando Z, Davide A, Roberto S, Valeria F, Raffaella A, Antonio A. Influence of tooth preparation design on the stress distribution in maxillary central incisors restored by means of alumina porcelain veneers: A 3D-finite element analysis. J Dental Mater 2005; 21: 1178-1188.

[21] Shihab AR, Raheel Malik, Stephen MD. Stress Analysis of Occlusal Forces in Canine Teeth and Their Role in the Development of Non-Carious Cervical Lesions: Abfraction. Int $\mathrm{j}$ Dent. 2012; 2012: 1-7.

[22] Oguz E, Ozgur I, Asli S. The effect of framework design on stress distribution in implant supported FPDs: A 3-D FEM study. Eur J Dent. 2010; 4(4): 374-82. 
[23] Rouse, j. Full veneer versus traditional veneer preparation: A discussion of interproximal extension. J Prosthet Dent 1997; 78: 545-9.

[24] Friedman M J. A 15 year review of porcelain veneer failures - A clinician's observations. Compend Contin Educ Dent 1998; 19 : 625-36.

[25] Castelnuovo J. Fracture load and mode of failure of ceramic veneers with different preparations. J prosthet Dent. 2000; 83: 171-80.

[26] Seymour K. Stresses within porcelain veneers and the composite lute using differen preparation designs. J Prosthod. 2001; 10: 16-21.

[27] khatib D. Fracture load of two cad/cam ceramic veneers with different preparation designs. Cairo Dental Journal.2009; 25: 425:432.
[28] Zarone F, Sorrentino R, Apicella D. Valentino B, Ferrari M, Aversa $\mathrm{R}$ et al. Evaluation of the biomechanical behavior of maxillary central incisors restored by means of endocrowns compared to a natural tooth: a 3D static linear finite element analysis. Dent. Mater. 2006; 22: 1035-44.

[29] Troedson M, Dérand T. Shear stresses in the adhesive layer under porcelain veneers. A finite element method study. Acta Odontol. Scand. 1998; 56: 257-262.

[30] Lin, T. Fracture resistance and marginal discrepancy of porcelain laminate veneers influenced by preparation design and restorative material in vitro. J Dent.2012; 40: 202-209.

[31] Chander T, Padmanabhan V. Finite element stress analysis of diastema closure with ceramic laminate veneers. J Prosthod.2009; 18: $577-581$. 